\title{
Effectiveness of multifaceted fall-prevention programs for the elderly in residential care
}

\author{
M D Cusimano, J Kwok and K Spadafora \\ Inj. Prev. 2008;14;113-122 \\ doi:10.1136/ip.2007.017533
}

Updated information and services can be found at:

http://injuryprevention.bmj.com/cgi/content/full/14/2/113

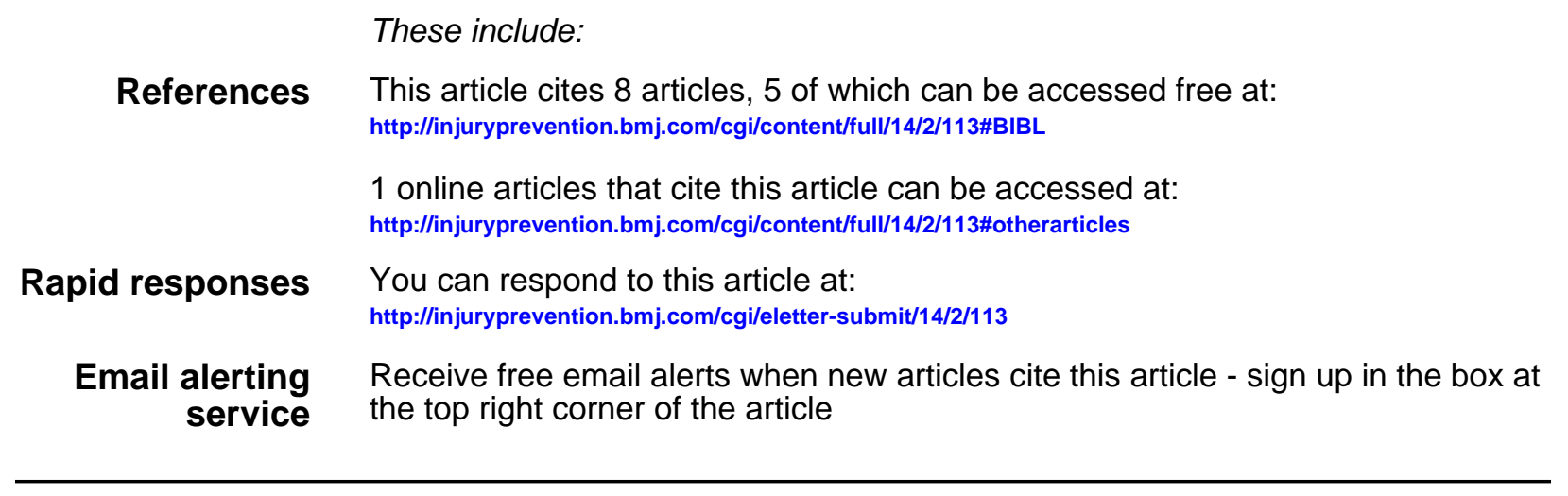

Notes

To order reprints of this article go to:

http://journals.bmj.com/cgi/reprintform

To subscribe to Injury Prevention go to:

http:/journals.bmj.com/subscriptions/ 


\title{
Effectiveness of multifaceted fall-prevention programs for the elderly in residential care
}

\author{
M D Cusimano, ${ }^{1}$ J Kwok, ${ }^{2}$ K Spadafora ${ }^{2}$
}

${ }^{1}$ Injury Prevention Research Office, Li Ka Shing Knowledge Institute, Keenan Research Centre, St Michael's Hospital, University of Toronto, Toronto, Ontario, Canada; ${ }^{2}$ University of Toronto, Toronto, Ontario, Canada

Correspondence to:

Dr M Cusimano, 2 Queen Street East, 10th floor, Suite 10-05i, Toronto, ON, Canada, M5C 3G7; CUSIMANOM@smh.toronto. on.ca

Accepted 22 January 2008

\begin{abstract}
Background: Unintentional falls are particularly prevalent among older people and constitute a public health concern. Not much is known about the implications of multifaceted intervention programs implemented in residential care settings.
\end{abstract}

Objectives: To evaluate the effectiveness of multifaceted intervention programs in reducing the number of falls, fallers, recurrent fallers, and injurious falls among older people living in residential care facilities.

Search strategy: Comprehensive searches of Medline, PubMed, and EMBASE up to July 2007, the cited literature lists of each included study, and the internet engines Google Scholar, Yahoo, and Dogpile were performed to identify eligible studies.

Selection criteria: Eligible studies for this review were those that had randomized, controlled trials with adequate follow-up study components in their design. Studies that included elderly people in residential care who participated in multifaceted falls-prevention programs were included.

Data collection and analysis: Two authors independently extracted the necessary data. Studies were assessed for quality by the criteria of Downs and Black. The results of the included studies have been reviewed narratively.

Main results: From 21 articles potentially relevant to the topic, five studies met the inclusion criteria and all were reasonably well conducted. Three reported significant reductions in the number of recurrent fallers, two reported significant reductions in the number of falls, and one reported significant reductions in the number of fallers. One other reported a reduction in the number of injurious falls in those who received the multifaceted prevention program compared with the control group. However, the analyses of this specific study were not based on intentto-treat, so the effect of intervention on the number of injurious falls remains inconclusive. No study reported on adverse events, costs, or sustainability of the interventions.

Conclusions: Multifaceted programs that encompass a wide range of intervention strategies have shown some evidence of efficacy. However, more well-designed research is required that assesses effects on injurious falls, quality of life, cost-effectiveness, and sustainability.

Falls in the elderly are a rising concern in society, as their incidence is expected to increase with the ageing "baby boom" generation. Moller ${ }^{1}$ anticipates that the total health costs attributable to injurious falls in elderly people will increase threefold in the next 50 years in Australia alongside significant increases in nursing home places and additional hospital bed days. Recent studies in the USA have shown that falls among older people are the reason for $10 \%$ of all visits to emergency departments and $6 \%$ of urgent hospitalizations. ${ }^{2}$ The elderly living in long-term care facilities are at a higher risk of falling than community-dwelling elderly. The incidence of falls in residential care facilities is approximately three times higher than that in the community, equating to about 1.4 falls per person per year. ${ }^{3}$ Injuries such as hip fractures have an in-hospital mortality of $15 \%$ and a 1 -year survival of only two-thirds. ${ }^{4}$

There is evidence to suggest that these costly falls are preventable through the design and implementation of multifaceted falls-intervention programs. ${ }^{5}$ These programs typically entail staff and resident education, environmental modification, exercise programs, medication reviews, and other intervention strategies. Multifaceted fallsprevention programs have mainly been implemented for community-dwelling older people and with more success than programs using single-strategy interventions. ${ }^{6}$ There is thus a need to see whether importing these multifaceted programs into the residential care setting will yield similar results. Although single interventions such as exercise and home hazard assessments are known to be efficacious by themselves, ${ }^{6}$ "falls are often the result of a complex, interdependent constellation of factors, resulting in multiple causes acting together to produce a fall." " Therefore, fallsprevention programs that are multifaceted, in that they include more than one implemented intervention strategy to attempt to reduce predisposing and situational risk factors for falling caused by both the surrounding environment and the resident's behavior, are entirely justified.

This systematic review is unique in several regards. It focuses exclusively on multifaceted falls-intervention programs in residential care facilities, unlike previous reviews. ${ }^{38}$ This restriction is consistent with the growing trend towards nursing homes in developed countries such as the USA where $40 \%$ of people aged 65 years or older are expected to use a residential care facility at some point in their lives. ${ }^{9}$

Also, unlike previous reviews on the efficacy of multifaceted falls-intervention programs, our paper takes into account the number of recurrent fallers because of their frequency and potential contribution to the problem. It is important to study the number of recurrent fallers because they contribute considerably to the total number of falls recorded. Vassallo and colleagues ${ }^{10}$ found that, compared with non-fallers, recurrent fallers were more likely to have pre-admission falls $(p=0.004)$, longer stays in hospital $(p<0.001)$, and more nursing home discharges $(p<0.001)$. Recurrent fallers are therefore 
a high-risk group and contribute significantly to the overall health burden caused by falls in the elderly.

The objective of this review is to evaluate the effectiveness of multifaceted intervention programs in reducing the number of falls, fallers, recurrent fallers, and injurious falls among elderly people living in residential care facilities.

\section{METHODS}

Table 1 presents the definitions of terms used in this review.

\section{Inclusion criteria}

1. Randomized controlled trials

2. Concurrent comparison group

3. Participants who were all 60 years of age or older living in a residential care setting including nursing homes

4. Multifaceted programs, which included more than one intervention strategy; common strategies include: staff/ resident education on falls prevention, environmental modification, exercise programs, medication review, the supply of (free) hip protectors, and maintenance of mobility-related aids such as wheelchairs

5. At least a 6-month follow-up period for evaluation of residents after the intervention program (eg, post-fall assessments, monitoring of falls and fractures)

6. Studies that measure at least one of the following outcomes: the number of residents sustaining a fall, number of falls, number of injuries (eg, fractures, brain injuries) resulting from falls, and number of recurrent fallers

\section{Exclusion criteria}

1. No concurrent comparison group

2. Studies where the primary setting is not residential care such as nursing homes

3. Intervention programs that only focus on one strategy hence not multifaceted

4. Studies that only report proxies such as postural hypotension or the risk of falling

5. Non-peer-reviewed reports

\section{Search strategies}

We searched the following electronic databases: Medline (to July 2007); PubMed (to July 2007); EMBASE (to July 2007); CINAHL (to July 2007).

Keywords searched were: "falls," "accidental falls," "prevention," "residential care," "hip fracture," "fracture," "brain injury," "head injury," "aged," "multifaceted," "trauma," "randomized controlled trial," "prophylaxis." Using a combination of medical subject headings and free text, articles were retrieved for preliminary consideration. The searches were not restricted by language or publication status.

The citation lists for all included studies and the internet search engines Dogpile, Yahoo, and Google Scholar were also searched.

\section{Study identification and selection}

The articles were screened using the inclusion and exclusion criteria. Of the initial 21 potential studies, five remained. The most common reasons for exclusion were exclusion criterion 1 (26\%), criterion $2(58 \%)$, criterion $3(11 \%)$, and criterion $4(5 \%)$. Disagreements were resolved through consensus.

\section{Data extraction}

Data were extracted independently by two authors (JK, KS).

\section{Description of search}

The full text of 21 studies was retrieved for preliminary consideration; five met the inclusion criteria.

\section{Quality assessment}

Methodological quality was assessed using the Downs and Black checklist. ${ }^{13}$ The five main areas assessed were: reporting, external validity, bias (internal validity), confounding (internal validity), and power.

\section{RESULTS \\ Description of studies \\ Jensen et $a l^{5}$}

In this study, the residents $(n=402)$ were from nine residential care homes in a northern city in Sweden. The participants in

Table 1 Definitions

\begin{tabular}{|c|c|}
\hline Term & Corresponding definition \\
\hline Effectiveness & $\begin{array}{l}\text { A statistically significant reduction in the value of any one of the main outcomes listed } \\
\text { under inclusion criterion No } 6 \text { when control and intervention groups are compared. }\end{array}$ \\
\hline Multifaceted intervention programs & $\begin{array}{l}\text { Programs that include more than one implemented intervention strategy to assess and } \\
\text { attempt to reduce predisposing and situational risk factors for falling caused by both the } \\
\text { surrounding environment and the resident's behavior. Environmental strategies include } \\
\text { home hazard assessments, and behavioral strategies include falls-prevention education, } \\
\text { exercise programs, medication reviews, etc. An intervention program that uses both falls- } \\
\text { prevention education and environmental modification is said to be multifaceted. } \\
\text { Intervention programs that use only one strategy (eg, falls-prevention education) are said to } \\
\text { be single-strategy interventions. }\end{array}$ \\
\hline Falls & $\begin{array}{l}\text { Events in which the resident unintentionally comes to rest on the ground or floor, } \\
\text { regardless of whether an injury is sustained. }\end{array}$ \\
\hline Elderly & Individuals who are 60 years of age or older \\
\hline Residential care/nursing homes & $\begin{array}{l}\text { Institutions that provide congregate living for the elderly, most of whom require assistance } \\
\text { with daily living, namely only long-term care facilities and nursing homes }\end{array}$ \\
\hline Injurious falls & $\begin{array}{l}\text { The definition of injurious falls has differed substantially in the literature because of } \\
\text { differences in whether minor injuries such as bruises and cuts are classified as fall-related } \\
\text { injuries. The Prevention of Falls Network Europe collaborators recommends that the most } \\
\text { rigorous definition of a serious fall-related injury is radiologically confirmed peripheral } \\
\text { fracture, ie, fractures of the limbs and limb girdles. }{ }^{11} \text { We have also included other serious } \\
\text { injuries such as traumatic brain injuries. }\end{array}$ \\
\hline Recurrent fallers & Residents with two or more falls in a given time period (eg, a year). \\
\hline
\end{tabular}


Table 2 Characteristics of included studies

\begin{tabular}{|c|c|}
\hline Study & Characteristics \\
\hline \multicolumn{2}{|l|}{ Jensen et $a l^{5}$} \\
\hline Methods & Cluster randomized, controlled, trial \\
\hline Participants & $\begin{array}{l}\text { Residents, aged } 65 \text { years or older, in nine residential care facilities in Sweden } \\
\text { Intervention: } 194 \text { residents }\end{array}$ \\
\hline Eligibility & $\begin{array}{l}402 \text { residents; selected in cross-sectional manner; selected facilities had to have more than } \\
25 \text { residents }\end{array}$ \\
\hline Duration of intervention program & 11 weeks \\
\hline $\begin{array}{l}\text { Topics received by intervention } \\
\text { group (delivery method in } \\
\text { parentheses) }\end{array}$ & $\begin{array}{l}\text { Residents received: } \\
\text { Environmental modification for all (general) } \\
\text { Exercise program for } 70 \text { residents (resident-specific) } \\
\text { Medication adjustments for } 21 \text { residents with suspected side effects believed to } \\
\text { increase risk for falling (resident-specific) } \\
\text { Provision and repair of aids for } 29 \text { residents (resident-specific) } \\
\text { Provision of free hip protectors for } 47 \text { residents prone to fall-related hip fractures, } 34 \text { of } \\
\text { which agreed to use them (resident-specific)Staff received: } \\
\text { All staff were invited to a falls-prevention educational session (group); more than } 50 \% \\
\text { of invited staff attended }\end{array}$ \\
\hline $\begin{array}{l}\text { Description of intervention that } \\
\text { control group received }\end{array}$ & $\begin{array}{l}\text { The residents in the control group received usual care: ie, the tasks of the physiotherapist } \\
\text { were not changed and no hip protectors were provided; no systematic fall-related problem- } \\
\text { solving conferences or major fall-related environmental modifications were provided }\end{array}$ \\
\hline Outcomes measured & $\begin{array}{l}\text { The number of residents sustaining a fall, the number of falls, the time to occurrence of the } \\
\text { first fall, and the number of injuries resulting from falls }\end{array}$ \\
\hline Main results & $\begin{array}{l}\text { Fewer residents in the intervention group endured falls compared with the control group: } \\
82 \text { of } 188(44 \%) \text { compared with } 109 \text { of } 196(56 \%) \text {; this represents a risk ratio of } 0.78(95 \% \\
\text { Cl } 0.64 \text { to } 0.96)\end{array}$ \\
\hline Cluster & Nursing home \\
\hline Statistical analyses & Adjusted for clustering \\
\hline Randomization method & $\begin{array}{l}\text { Random allocation conducted by person with no knowledge of study; two sealed, dark } \\
\text { envelopes were used with a letter specifying a group (either control or intervention) }\end{array}$ \\
\hline Allocation concealment & A: adequate \\
\hline $\begin{array}{l}\text { Resident length of follow-up in } \\
\text { control group }\end{array}$ & 34 weeks \\
\hline $\begin{array}{l}\text { Resident length of follow-up in } \\
\text { intervention group }\end{array}$ & 34 weeks \\
\hline Notes & $\begin{array}{l}\text { Unclear whether the intervention residents who received exercise programs also received } \\
\text { free hip protectors and medication reviews }\end{array}$ \\
\hline \multicolumn{2}{|l|}{ Becker et $a l^{14}$} \\
\hline Methods & Cluster randomized, controlled trial \\
\hline Participants & $\begin{array}{l}\text { Long-stay residents, aged } 60 \text { and older, in six nursing homes in Germany } \\
\text { Intervention: } 509 \text { residents } \\
\text { Control: } 472 \text { residents }\end{array}$ \\
\hline Eligibility & $\begin{array}{l}981 \text { residents; all aged } 60 \text { years or older living in one of six long-term care institutions for } \\
\text { more than } 4 \text { weeks during the intervention period; no inclusion/exclusion criteria based on } \\
\text { function or cognitive status }\end{array}$ \\
\hline Duration of intervention program & 1 year \\
\hline $\begin{array}{l}\text { Topics received by intervention } \\
\text { group (delivery method in } \\
\text { parentheses) }\end{array}$ & $\begin{array}{l}\text { Residents received: } \\
\text { Written educational information on falls prevention for all residents (general) } \\
\text { orsonal educational consultation on falls prevention for residents who were not chair- } \\
\text { or bednd (resident-specific) } \\
\text { Environmental modification for all (general) } \\
\text { Exercise program for those who could at least stand while holding on to a chair and lift } \\
\text { one foot; this was received by } 167 \text { residents (group) } \\
\text { Hip protectors for those who could stand at least assisted or who occasionally tried to } \\
\text { rise form a chair unattended; this was received by } 160 \text { residents (individual- } \\
\text { specific)Staff received: }\end{array}$ \\
\hline $\begin{array}{l}\text { Description of intervention that } \\
\text { control group received }\end{array}$ & No specific program activities in control facilities \\
\hline Outcomes measured & Incidence density rate of falls, recurrent fallers, and hip fractures (injurious falls) \\
\hline \multirow[t]{2}{*}{ Main results } & $\begin{array}{l}\text { Incidence density rate of falls per } 1000 \text { resident years: } 1399 \text { (intervention) and } 2558 \\
\text { (control) }(p<0.001)\end{array}$ \\
\hline & $\begin{array}{l}\text { Incidence density rate of fallers detected: } 247(52.3 \%) \text { in control and } 188(36.9 \%) \text { in the } \\
\text { intervention }(p=0.038)\end{array}$ \\
\hline Cluster & Nursing home \\
\hline Statistical analyses & Adjusted for clustering \\
\hline Randomization method & $\begin{array}{l}\text { Randomization was performed under supervision of a representative of the city government } \\
\text { using sealed envelopes }\end{array}$ \\
\hline
\end{tabular}


Table 2 Continued

\begin{tabular}{ll}
\hline Study & Characteristics \\
\hline $\begin{array}{l}\text { Allocation concealment } \\
\text { Resident length of follow-up in } \\
\text { control group }\end{array}$ & $\begin{array}{l}\text { A: adequate } \\
1 \text { year }\end{array}$ \\
$\begin{array}{l}\text { Resident length of follow-up in } \\
\text { intervention group }\end{array}$ & 1 year \\
Notes & $\begin{array}{l}\text { Justification was not provided by authors as to why above stated requirements were } \\
\text { implemented for participation in exercise programs and hip protector provision }\end{array}$
\end{tabular}

Dyer et $a l^{15}$
Methods
Participants

Eligibility

Duration of intervention program Topics received by intervention group (delivery method in parentheses)

Description of intervention that control group received

Outcomes measured

Main results

Cluster

Statistical analyses

Randomization method

Allocation concealment

Resident length of follow-up in control

Resident length of follow-up in intervention

Notes

\section{McMurdo et $\left.a\right|^{16}$ \\ Methods \\ Participants}

Eligibility

Duration of intervention program

Topics intervention group received (delivery method in parentheses)

Description of intervention that control group received

Outcomes measured

Main results
Cluster randomized, controlled trial

Residents, aged 60 years or over, in 20 residential care homes in west Wiltshire, England. Intervention: 102 residents

Control: 94 residents

196 residents; all living in single registered residential homes for older people (minimum of five residents per home) which did not specialize in the mentally ill; exclusion of temporary residents and those suffering from a clearly defined terminal illness

\section{2-14 weeks}

Residents received:

- Environmental modification for all (general)

- Exercise program for 83 participants (group)

- Medication reviews for those with suspected medical risk factors (resident-specific)

- Optician reviews for those having a visual acuity of $6 / 12$ or less, podiatry for those whose had concerns over foot condition (resident-specific)Staff received:

- Falls-prevention education (general)

Control group received no intervention but was visited every 3 weeks by research assistant to ensure completion of falls records

Primary outcomes measured: the number of falls/recurrent falls per person and the number of drugs per year. Secondary outcome measured: the change in Tinetti gait and balance

A mean of 2.2 falls per resident per year was observed in the intervention group compared with 4.0 in the control group; this failed to reach statistical significance $(p<0.2)$ once the intracluster correlation $(0.10)$ had been accounted for. This is potentially related to the study power, baseline differences between the groups, and individual differences within the residential homes

Nursing home

Adjusted for clustering

Allocation sequence generated from computer-generated random number tables; allocation sequences were performed and kept secure by a researcher (independent of study)

A: adequate

1 year

1 year

The relatively high intracluster correlation coefficients in this study suggest that the environment (ie, the nursing home) had a major effect on fall rates

Unclear on the proportion of participants that received exercise programs who also received medication adjustments, and various assessments

Cluster randomized, controlled trial

Residents, aged 70 years or older, in nine residential homes in Scotland

Intervention: 77 residents

Control: 56 residents

334 residents; individuals aged 70 years or older living in residential homes invited to take part, the only exclusion criterion being a Mini-Mental State Examination less than 12

6 months

Residents received: (it was not reported as to how many participants actually received each facet)

- Environment modification, with a focus on appropriate lighting (general)

- Medication review (resident-specific)

- Twice weekly, 30-min exercise sessions (group)

For 6 months, residents in the control group participated in a twice-weekly, 30 min reminiscence group; sessions designed to promote social interaction and included use of quizzes, music, archive material

The number of falls sustained, the risk of falling, and recurrent falling as measured by postural hypotension and visual acuity in the intervention group

No difference observed between the intervention and control groups in the number of falls sustained ( $p$ value not reported). Residents who sustained a fall represented $58 \%$ of the control group and $38 \%$ of the intervention group $(p=0.088)$

Nursing home 
Table 2 Continued

\begin{tabular}{|c|c|}
\hline Study & Characteristics \\
\hline Statistical analyses & Not adjusted for clustering \\
\hline Randomization method & Details not reported \\
\hline Allocation concealment & B: unclear \\
\hline $\begin{array}{l}\text { Resident length of follow-up in } \\
\text { control }\end{array}$ & 6 months \\
\hline $\begin{array}{l}\text { Resident length of follow-up in } \\
\text { intervention }\end{array}$ & 6 months \\
\hline Notes & High drop-out rate undermined power of the study to detect interventions' various effects \\
\hline \multicolumn{2}{|l|}{ Ray et $a l^{12}$} \\
\hline Methods & Cluster randomized, controlled trial \\
\hline Participants & $\begin{array}{l}\text { Residents, aged } 65 \text { years or older, in seven pairs of Tennessee nursing homes } \\
\text { Intervention: } 221 \text { residents } \\
\text { Control: } 261 \text { residents }\end{array}$ \\
\hline Eligibility & $\begin{array}{l}482 \text { residents; before randomization, residents who were younger than } 65 \text { years, who were } \\
\text { not expected to remain in the homes at least } 6 \text { months, who were bed-bound, or who had } \\
\text { no fall in the past } 365 \text { days were excluded }\end{array}$ \\
\hline Duration of intervention program & 1 year \\
\hline $\begin{array}{l}\text { Topics received by intervention } \\
\text { group (delivery method in } \\
\text { parentheses) }\end{array}$ & $\begin{array}{l}\text { Residents received: } \\
\text { Environmental modification for all (general) } \\
\text { Education on safer transferring techniques for all (general) } \\
\text { Drug regimen review for high-risk residents from pre-existing data (resident-specific) } \\
\text { Wheelchair maintenance for all users (resident-specific)Staff received: } \\
\text { Education on safer transferring techniques (general) }\end{array}$ \\
\hline $\begin{array}{l}\text { Description of intervention that } \\
\text { control group received }\end{array}$ & No program activities in matched control facility \\
\hline Outcomes measured & $\begin{array}{l}\text { The mean proportion of recurrent fallers and the incidence of injurious falls in the nursing } \\
\text { homes in the year after intervention }\end{array}$ \\
\hline Main results & $\begin{array}{l}\text { Mean proportion of recurrent fallers in intervention group }(43.8 \%) \text { was } 19.1 \% \text { lower than } \\
\text { that in control facilities }(54.1 \%)(p=0.03)\end{array}$ \\
\hline Cluster & Nursing home \\
\hline Statistical analyses & Adjusted for clustering \\
\hline Randomization method & Sealed envelope random assignments \\
\hline Allocation concealment & A: adequate \\
\hline $\begin{array}{l}\text { Resident length of follow-up in } \\
\text { control }\end{array}$ & 1 year \\
\hline $\begin{array}{l}\text { Resident length of follow-up in } \\
\text { intervention }\end{array}$ & 1 year \\
\hline Notes & $\begin{array}{l}\text { All eligible persons participated and interventions seem to have been applied to all } \\
\text { participants }\end{array}$ \\
\hline
\end{tabular}

both the intervention and control groups completed a baseline assessment. More than half of all invited staff in the intervention nursing homes attended a physician-and-physiotherapist-led educational seminar. Another intervention strategy, environmental modification, entailed reducing the environmental hazards in common areas by rearranging furniture that posed a risk for falling, among other things. The exercise program was delivered in the form of residenttailored training aimed at improving strength, balance, gait, and safe transfer. Finally, the drug regimen review strategy sought to adjust medication for residents because of the presence of side effects that could potentially enhance the risk of falling. The residents in the control group received the usual care.

\section{Becker et $a /^{14}$}

In this study, the sample consisted of 981 residents from six community nursing homes in Germany. The control group did not undergo any specific program activities during the intervention period. The participants in both the intervention and control groups completed a baseline assessment. Staff education in the intervention nursing homes comprised a 60 -min course delivered to staff members and the provision of written information on falls. Resident education also involved the provision of written information on falls prevention. For the environmental modification component, an environmental hazard check was completed with particular emphasis on appropriate lighting, chair and bed height, floor surfaces, room clutter, additional grab bars for toilets and bathrooms, and proper use and maintenance of walking aids. The group exercise program relied on a blend of balance exercises and progressive resistance training.

Dyer et $a l^{15}$

For this study, the sample consisted of 196 residents living in residential care homes in west Wiltshire, England. Before randomization, baseline assessments of participating residents and homes were conducted. The control group was visited every 3 weeks by the research assistant so that fall records would be complete. For the intervention group, staff education entailed the dissemination of written information pertaining to the study's objectives by the care home manager to the staff. Another feature, a 40-min group exercise program (thrice weekly for 12-14 weeks), involved offering physiotherapistsupported exercise sessions, which targeted balance and gait, flexibility, strength, and endurance. Environmental modification largely consisted of written reports, completed by an 
Table 3 Methodological quality

\begin{tabular}{|c|c|c|c|c|c|}
\hline Criteria of quality $^{13}$ & Jensen et $a l^{5}$ & Becker et $\mathrm{al}^{14}$ & Dyer et $a l^{15}$ & McMurdo et $a l^{16}$ & Ray et $a l^{\prime 2}$ \\
\hline $\begin{array}{l}\text { Reporting: is the hypothesis/aim/objective of the study } \\
\text { clearly described? }\end{array}$ & Yes & Yes & Yes & Yes & Yes \\
\hline $\begin{array}{l}\text { Reporting: are the main outcomes to be measured clearly } \\
\text { described in the introduction or methods section? }\end{array}$ & Yes & Yes & Yes & Yes & Yes \\
\hline $\begin{array}{l}\text { Reporting: are the characteristics of the patients included } \\
\text { in the study clearly described? }\end{array}$ & Yes & Yes & Yes & Yes & Yes \\
\hline Reporting: are the interventions of interest clearly described? & Yes & Yes & Yes & Yes & Yes \\
\hline Reporting: are the main findings of the study clearly described? & Yes & Yes & Yes & Yes & Yes \\
\hline $\begin{array}{l}\text { Reporting: does the study provide estimates of the random } \\
\text { variability in the data for the main outcomes? }\end{array}$ & Yes & Yes & Yes & Yes & Yes \\
\hline $\begin{array}{l}\text { Reporting: have all important adverse events that may be a } \\
\text { consequence of the intervention been reported? }\end{array}$ & No & No & No & No & No \\
\hline $\begin{array}{l}\text { Reporting: have the characteristics of patients lost to follow-up } \\
\text { been described? }\end{array}$ & Yes & Yes & Yes & $\begin{array}{l}\text { No: reported those that } \\
\text { dropped out but reasons } \\
\text { for dropping out not } \\
\text { reported }\end{array}$ & Yes \\
\hline $\begin{array}{l}\text { External validity: were the subjects asked to participate in } \\
\text { the study representative of the entire population from which } \\
\text { they were recruited? }\end{array}$ & Yes & Yes & Yes & Yes & Yes \\
\hline $\begin{array}{l}\text { External validity: were those subjects who were prepared to } \\
\text { participate representative of the entire population from which } \\
\text { they were recruited? }\end{array}$ & Yes & Yes & Yes & Yes & Yes \\
\hline $\begin{array}{l}\text { External validity: were the staff, places, and facilities where } \\
\text { the patients were treated, representative of the treatment } \\
\text { that most patients receive? }\end{array}$ & Yes & Yes & Yes & Yes & Yes \\
\hline $\begin{array}{l}\text { Internal validity: was an attempt made to blind study subjects } \\
\text { to the intervention they have received? }\end{array}$ & No & No & No & No & No \\
\hline $\begin{array}{l}\text { Internal validity: was an attempt made to blind those } \\
\text { measuring the main outcomes of the intervention? }\end{array}$ & No & No & No & No & No \\
\hline Internal validity: was compliance with the intervention/s reliable? & Yes & Yes & Yes & Yes & Yes \\
\hline $\begin{array}{l}\text { Internal validity: were the main outcome measures used accurate } \\
\text { (valid and reliable)? }\end{array}$ & Yes & Yes & Yes & Yes & Yes \\
\hline $\begin{array}{l}\text { Internal validity: were the patients in different intervention groups } \\
\text { (trial and cohorts studies) or were the cases and control } \\
\text { (case-control studies) recruited from the same population? }\end{array}$ & Yes & Yes & Yes & Yes & Yes \\
\hline $\begin{array}{l}\text { Internal validity: were the patients in different intervention groups } \\
\text { (trials and cohorts studies) or were the cases and control } \\
\text { (case-control studies) recruited over the same period of time? }\end{array}$ & Yes & Yes & Yes & Yes & Yes \\
\hline $\begin{array}{l}\text { Internal validity: were the study subjects randomized to intervention } \\
\text { groups? }\end{array}$ & Yes & Yes & Yes & Yes & Yes \\
\hline $\begin{array}{l}\text { Internal validity: was the randomized intervention assignment } \\
\text { concealed from both patients and healthcare staff until recruitment } \\
\text { was complete and irrevocable? }\end{array}$ & Yes & Yes & Yes & $\begin{array}{l}\text { Unclear (was not } \\
\text { reported by authors) }\end{array}$ & Yes \\
\hline $\begin{array}{l}\text { Internal validity: was there adequate adjustment for confounding } \\
\text { in the analyses from which the main drawings were drawn? }\end{array}$ & $\begin{array}{l}\text { No: main conclusions of } \\
\text { study based on analyses } \\
\text { of treatment rather than } \\
\text { intention-to-treat }\end{array}$ & Yes & Yes & Yes & Yes \\
\hline $\begin{array}{l}\text { Internal validity: were losses of patients to follow-up taken into } \\
\text { account? }\end{array}$ & Yes & Yes & Yes & Yes & Yes \\
\hline $\begin{array}{l}\text { Power: did the study have sufficient power to detect a clinically } \\
\text { important effect where the probability value for a difference being } \\
\text { due to chance is }<5 \% \text { ? }\end{array}$ & Yes & Yes & No & No & Yes \\
\hline
\end{tabular}


Table 4 Significance of losses of patients to follow-up for included studies

\begin{tabular}{lll}
\hline Study & $\begin{array}{l}\text { Proportion of patients lost to } \\
\text { follow-up in control group (\%) }\end{array}$ & $\begin{array}{l}\text { Proportion of patients lost to } \\
\text { follow-up in intervention group (\%) }\end{array}$ \\
\hline Jensen et $a l^{5}$ & 41 of 208 total residents $(19.7 \%)$ & 37 of 194 total residents $(19.0 \%)$ \\
Becker $e t a^{14}$ & 82 of 472 total residents $(17.4 \%)$ & 98 of 509 total residents $(19.3 \%)$ \\
Dyer et $a l^{15}$ & 11 of 94 total residents $(11.7 \%)$ & 13 of 102 total residents $(12.7 \%)$ \\
McMurdo et $a l^{16}$ & 18 of 56 total residents $(32.1 \%)$ & 30 of 77 total residents $(39.0 \%)$ \\
Ray et $a l^{12}$ & 6 of 267 total residents $(2.2 \%)$ & 11 of 232 total residents $(4.7 \%)$ \\
\hline
\end{tabular}

occupational therapist assistant, on specific risk factors. Medication reviews were advised for residents with suspected medical risk factors.

\section{McMurdo et $a l^{16}$}

This study reported on 133 residents in nine local authority residential homes in Dundee, Scotland. The control group received 6 months of reminiscence therapy while the intervention group received 6 months of falls risk factor assessment/ modification and a seated balance exercise training program. In the former group, the reminiscence sessions entailed participation in a twice-weekly gathering to promote social interaction through the use of quizzes and music among other items. The risk factor assessment/modification incorporated environmental modification, with a specific focus on appropriate lighting, in addition to medication reviews. Medication that could have contributed to hypotension in the residents was reviewed, and dose reduction, discontinuation, or therapeutic substitution was recommended as necessary (this was not formally done for the control group). The exercise feature of the intervention program was a twice-weekly, 30-min seated group exercise session to music.

\section{Ray et $a l^{12}$}

This study reported on 482 residents in seven pairs of Tennessee nursing homes. For the intervention group, an individualized treatment plan was developed after preliminary assessments, and each nursing home chose a falls coordinator, who was responsible for implementing the recommendations stated on the treatment plan. The environmental modification strategy entailed safety recommendations on modifying the lighting, flooring, and call lights, and a suggestion to purchase raised toilet seats which would ensure a safer bathroom setting. Another feature of the multifaceted program was drug regimen reviews in which a team reviewed the suitability of psychotropic drug use among regular users who were ambulatory and at high risk of falling. The educational component offered instruction pertaining to safer transferring techniques to residents and staff. The control group did not undergo any program activities.

Table 2 provides a summary of the following components in each of the studies: methods, participants, eligibility, duration of intervention, topics received by intervention group and the delivery method, control group activities, outcomes measured, main results, cluster, statistical analyses, randomization method, allocation concealment, follow-up period, and any additional notes.

The performance of the included studies in each of these areas is discussed below and summarized in table 3 .

\section{Reporting}

Reporting was adequate for all the included studies. This included reporting of the study hypothesis, the main outcomes and interventions, estimates of random variability, and main findings. However, none of the included studies attempted to report the adverse effects associated with the undertaken intervention strategies such as cardiac events or falls during the exercise component of the programs. None reported on costs or sustainability of the multifaceted interventions.

\section{Internal validity}

As the study population and the study investigators could not be blinded with respect to the intervention, concern for internal validity bias is present. However, the absence of concealment was due to the nature of the intervention itself, and the studies were carried out with otherwise sound methods (appropriate statistical tests, reliable compliance with intervention measures, valid outcome measures).

In all the included studies, apart from one, all patients in the residential care facilities were given the option to participate. McMurdo et $a l^{16}$ did not report on this aspect of consent.

\section{Bias and confounding}

All the examined studies stated that the control groups were not exposed to any aspect of the intervention strategies. However, in our opinion, it is not clear from the reported studies as to whether there was the potential for contamination of the control groups. For example, staff who received educational sessions may have worked in both intervention and control nursing homes. Although residents had different doctors, it is possible that doctors in the intervention nursing homes could have communicated with doctors in the control nursing homes about reviewing/revising medication. This may have inadvertently contaminated the control groups.

Controls were recruited from the same populations as the intervention groups and over the same period of time, and the total number of potentially eligible patients was always reported. Losses of patients to follow-up were taken into account in all studies (table 4). However, the internal validity for one of the studies may have been threatened by the inadequate adjustment for confounding in the analyses from which the main findings were drawn. ${ }^{5}$ This study by Jensen and colleagues proposed conclusions that were based on analyses of treatment rather than intention-to-treat.

\section{Statistical power}

Three studies reported having sufficient power to detect a clinically important effect where the probability of a difference being due to chance is less than 5\%. ${ }^{52^{11}}{ }^{14}$ Jensen et al ${ }^{5}$ determined that their sample size (167 residents in the control group and 157 residents in the intervention group) was sufficiently powered to detect a $12 \%$ difference in falling between the two groups at a significance level of 0.05 .

The study of Becker et $a^{14}$ was underpowered to detect differences in fractures because of the low incidence of hip 


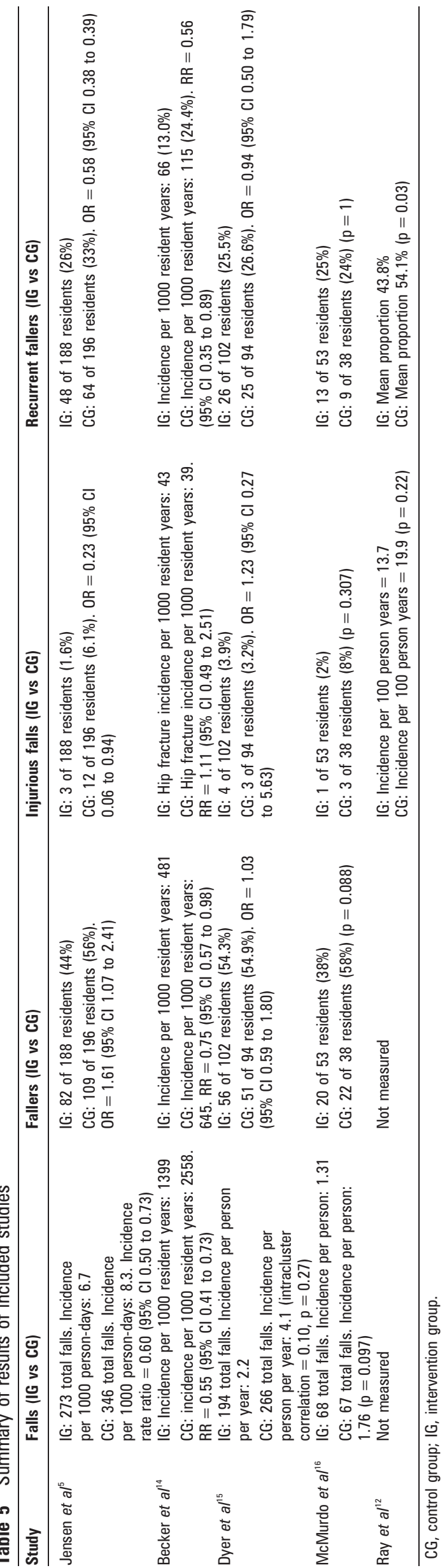

fractures in the control group and in the total group. However, there was adequate power to observe a significant difference in the rate of falls and recurrent fallers between the control and intervention groups using 95\% CI (table 5). Furthermore, the larger sample sizes used in this study pose fewer problems concerning its statistical power. ${ }^{14}$

Ray et $a^{12}$ designed their study so that a total sample size of 500 residents would provide power to detect a $20 \%$ reduction in recurrent fallers and a $35 \%$ reduction in injurious falls. The study was sufficiently powered to detect a significant reduction in recurrent fallers in intervention facilities compared with control facilities. However, it was inadequately powered to detect a significant reduction in injurious falls.

Dyer et $a 1^{15}$ noted that the relatively high intracluster correlation coefficient in their study might be linked to its low statistical power. The intracluster correlation coefficient measures how similarly residents within a cluster are behaving and therefore how much of the behavior is attributed to the cluster, in this case the nursing home, as opposed to the intervention program. Higher coefficients give lower power, with a coefficient of zero signifying that each patient was acting independently in response to the intervention. The high coefficients in this study indicate that the nursing home had a major effect on fall rates, therefore undermining its power to detect any statistically significant reduction in falls in the intervention group.

For the study of McMurdo et al, ${ }^{16}$ the high drop-out rate may have produced a type II error. In addition, see table 4.

\section{Data analysis}

Data were available as measures of comparison between control and intervention groups in the number of residents sustaining a fall, number of falls, number of injuries (eg, fractures) resulting from falls, and number of recurrent fallers. One study chose to express the outcomes (eg, falls and fallers) in terms of incidence density rates, defined as incidence of falls per 1000 resident years. ${ }^{14}$ In the study of Ray et al, ${ }^{12}$ differences between paired intervention and control homes were expressed as mean facility proportions of recurrent fallers.

A narrative approach was adopted to describe and synthesize the results because of the heterogeneity of the data of samples and uniqueness of methodological design (eg, follow-up periods) for each included study. The narrative approach was also adopted because no single prevention program used exactly the same combination of intervention strategies.

\section{Effect measures}

In the study of Becker et al, ${ }^{14}$ there was an unexpectedly low incidence of hip fractures in the control group, possibly underpowering the study for detecting significant differences in this particular injury. Another possible explanation for the results in this study was the low adherence to hip protectors. Residents who chose to wear hip protectors apparently observed a lack of staff support with toileting, dressing, and the supply of hip protectors during the initial intervention period.

Jensen $e t a l^{5}$ and Ray et $a l^{12}$ both defined recurrent fallers in their studies to be residents who sustained two or more falls during the follow-up period. The other three studies defined recurrent fallers to be residents who sustained three or more falls during the follow-up period. ${ }^{14} 1516$

Table 5 summarizes the results of the outcome measures for each of the included study areas. 


\section{DISCUSSION}

This review found evidence that multifaceted falls-intervention programs can significantly reduce the number of recurrent fallers and incidence of falls among the elderly living in residential care facilities. Of the four studies that measured the number of fallers and number of falls, both Jensen et $a l^{5}$ and Becker et a $1^{14}$ reported a significant reduction in both outcomes with the implementation of a multifaceted program. Only Jensen et a ${ }^{5}$ reported a significant reduction in the number of injurious falls with the implementation of the intervention program. However, the analyses of this study were not based on intent-to-treat, so the results on the number of injurious falls remain inconclusive.

Other confounding factors may also explain the decrease in the reported falls, injurious falls, fallers, and recurrent fallers besides the intervention program. Dyer et a ${ }^{15}$ commented that marked differences in the philosophy of residential care homes (to provide care or promote autonomy) may have a significant effect on the degree of enforcement of the multifaceted programs and therefore may have influenced outcomes.

Despite the health burden of recurrent fallers, there is still no agreed definition of what constitutes a "recurrent faller". Sensitivity analyses using receiver operator characteristic analyses of large databases of fallers might help to define this in a more valid way. All five of the included studies attempted to evaluate the efficacy of multifaceted intervention programs on reducing the number of recurrent fallers in residential care. Three of the studies reported a significant reduction in the number of recurrent fallers of $7-11 \%$ with the implementation of a multifaceted falls-intervention program. ${ }^{512} 14$ More highquality studies that measure this outcome are required.

Although the ageing demographic is a global phenomenon, none of the studies reviewed came from South America, Asia, Australia/Pacific or Africa. No study came from a middle- or low-income country. The data represent the findings of highincome nations in the Northern Hemisphere. If any global impact is to be made on this pressing problem, further research is required from an international community.

One of the strengths of this review is the high standard of methodological quality required for the inclusion of studies. All of the included studies were controlled and had random assignments to control and intervention groups. Four of the five included studies performed analyses appropriate for cluster randomization. ${ }^{5} 1214$ Despite the methodological quality, there is still room for improvement, particularly in the powering of studies for injurious falls in the future.

\section{IMPLICATIONS}

\section{Practice}

The best available evidence, albeit limited in quantity and quality, suggests that a multifaceted intervention program,

\section{Key points}

- Overall, multifaceted falls-prevention programs aimed at elderly people in residential care have the potential to reduce the number of falls and recurrent fallers.

- Future studies with larger sample sizes and longer follow-up periods are needed to make conclusions about the effects of such programs on the incidence of injurious falls.

- Assessment of adverse outcomes, cost-effectiveness, and other novel outcomes of multifaceted fall-intervention programs should be given priority in future global research. comprising resident-specific, group-specific, and general intervention strategies designed for residents living in residential care facilities is likely to be effective in reducing falls. Residentspecific intervention strategies include drug regimen reviews for residents with specific side effects believed to increase the risk of falling. Group-specific strategies commonly take the form of group exercise sessions. General intervention strategies include resident and staff education on falls prevention and environmental modification to the nursing home to reduce safety hazards, which may increase the risk of falling. These are general strategies in the sense that they can be applied to a larger number of residents and staff.

In a setting of limited resources, a reasonable approach for practitioners would be to focus on high-risk groups such as recurrent fallers because they contribute substantially to the overall health burden caused by falls in the elderly. ${ }^{10}$ Studies included in this review showed that multifaceted programs significantly reduce the number of recurrent fallers. ${ }^{5}{ }^{12}{ }^{14}$ These studies shared common general intervention strategies including environmental modification and education on falls prevention and specific strategies tailored to the needs of individual residents, such as medication reviews and the provision of hip protectors for recurrent fallers. Certain aspects of these multifaceted programs may be easier and less costly than others to implement, but further work is required across different countries to confirm that this is the optimal combination that is consistently effective before a recommendation for widespread implementation of such programs.

\section{Research}

Within the setting studied, insufficient evidence exists on adverse outcomes (eg, adverse outcomes attributed to a medication change in a previously stable patient, or an adverse event induced by an exercise program in an otherwise frail elderly person), costs, cost-effectiveness, and sustainability of such programs. No data exist on the value of these programs outside of higher-income countries in North America or Europe. Consideration of adverse outcomes, long-term sustainability, and cost-effectiveness of these programs globally should be given priority in future studies with sufficient power to detect differences in injurious falls.

Other outcomes that could be considered in evaluating the effectiveness of such programs for the elderly in residential care in the future include benefits to patients' quality of life, social interactions, and reductions of adverse events such as cardiac events and drug interactions that could theoretically arise from interventions intended to reduce falls. An unexplored area for consideration is the effect that such programs can have on care givers and family/friends.

Given the growing demographic of the elderly globally, there is an urgent need for well-designed studies in these areas to inform widespread integration of multifaceted programs into residential settings.

Competing interests: None.

\section{REFERENCES}

1. Moller J. Projected costs of fall related injury to older persons due to demographic change in Australia 2003; Commonwealth Department of Health and Ageing. http:// www.health.gov.au/internet/wcms/publishing.nsf/Content/health-pubhlth-publicatdocument-falls_costs-cnt.htm/\$FILE/falls_costs.pdf (accessed 13 Feb 2008).

2. Tinetti ME. Preventing falls in elderly persons. N Engl J Med 2003;348:42-9.

3. Cameron I, Murray GR, Gillespie LD, et al. Interventions for preventing falls in older people in residential care facilities and hospitals (Protocol). Cochrane Database Syst Rev 2005; issue 3. 
4. McClure R, Turner C, Peel N, et al. Population-based interventions for the prevention of fall-related injuries in older people. Cochrane Database Syst Rev 2005; (1):CD004441

5. Jensen J, Lundin-Olsson $L$, Nyberg $L$, et al. Fall and injury prevention in older people living in residential care facilities. Ann Intern Med 2002;136:733-41.

6. Scott V. World Heath Organization report: falls prevention in older age. 2007. http:// www.who.int/ageing/projects/falls_prevention_older_age/en/index.html (accessed 13 Feb 2008).

7. Public Health Agency of Canada, Ottawa. Multifactorial interventions. 2006. http://www.phac-aspc.gc.ca/seniors-aines/pubs/best_practices/ bp_evidence_for_bp_6e.htm (accessed 13 Feb 2008).

8. Gillespie LD, Gillespie WJ, Robertson MC, et al. Interventions for preventing falls in elderly people. Cochrane Database Syst Rev 2003;(4):CD000340.

9. Agency for Healthcare Research and Quality. Long-term care: AHRO Focus on Research. 2002. http://www.ahrq.gov/news/focus/focltcare.htm (accessed 13 Feb 2008).
10. Vassallo M, Sharma JC, Allen SC. Characteristics of single fallers and recurrent fallers among hospital in-patients. Gerontology 2002;48:147-50.

11. Lord SR, Sherrington C, Menz HB, et al. Falls in older people. Cambridge: Cambridge University Press, 2007:5

12. Ray WA, Taylor JA, Meador KG, et al. A randomised trial of a consultation service to reduce falls in nursing homes. JAMA 1997;278:557-62.

13. Downs SH, Black N. The feasibility of creating a checklist for the assessment of the methodological quality both of randomised and non-randomised studies of health care interventions. J Epidemiol Community Health 1998;52:377-84.

14. Becker C, Kron M, Lindemann U, et al. Effectiveness of a multifaceted intervention on falls in nursing home residents. J Am Geriatr Soc 2003;51:306-13.

15. Dyer CAE, Taylor GJ, Reed M, et al. Falls prevention in residential care homes: a randomised controlled trial. Age Ageing 2004;33:596-602.

16. McMurdo MET, Millar AM, Daly F. A randomised controlled trial of fall prevention strategies in old peoples' homes. Gerontology 2000;46:83-7.

\section{Lacunae}

\section{Ad push credited for safer festivities}

Firecracker and other New Year-related injuries fell to their lowest level in 8 years after a government scare campaign advertised the long surgical saw and pliers used in amputations on victims, the Philippine health secretary said in January. The number of Filipinos injured by firecrackers and celebratory gunfire in end-of-year celebrations fell by nearly half to 446 compared with 2006, Health Secretary Francisco Duque III said. One man died after ingesting a firecracker, officials said. Many Filipinos believe that noisy New Year celebrations drive away evil.

Contributed by Anara Guard. From Associated Press. 